\title{
An observation-based estimate of the strength of rainfall-vegetation interactions in the Sahel
}

\author{
S. O. Los, ${ }^{1}$ G. P. Weedon, ${ }^{1}$ P. R. J. North, ${ }^{1}$ J. D. Kaduk, ${ }^{2}$ C. M. Taylor, ${ }^{3}$ \\ and P. M. $\mathrm{Cox}^{4}$ \\ Received 31 March 2006; revised 29 June 2006; accepted 6 July 2006; published 16 August 2006.
}

[1] Over the course of the twentieth century the African Sahel experienced large variations in annual precipitation; including the wet period during the 1950s and 1960s and the long-term drought during the 1970s and 1980s. Feedbacks between the land surface and atmosphere can affect rainfall variability at monthly, annual and decadal time scales. However, the strength of the coupling between the land surface and precipitation is still highly uncertain, with climate-model derived estimates differing by an order of magnitude. Here a statistical model of vegetation greenness is used to estimate the vegetation-rainfall coupling strength in the Sahel, based on monthly satellitederived vegetation index and meteorological data. Evidence is found for a positive feedback between vegetation and rainfall at the monthly time scale, and for a vegetation memory operating at the annual time scale. These vegetation-rainfall interactions increase the interannual variation in Sahelian precipitation; accounting for as much as $30 \%$ of the variability in annual precipitation in some hot spot regions between $15^{\circ}$ and $20^{\circ} \mathrm{N}$. Citation: Los, S. O., G. P. Weedon, P. R. J. North, J. D. Kaduk, C. M. Taylor, and P. M. Cox (2006), An observation-based estimate of the strength of rainfallvegetation interactions in the Sahel, Geophys. Res. Lett., 33, L16402, doi:10.1029/2006GL027065.

\section{Introduction}

[2] Several factors contribute to the year-to-year variability in precipitation in the Sahel [Nicholson, 2000], used here to indicate the region south of the Sahara that also includes the Sudanese zone. Models and observations show that regional and global sea surface temperature patterns force substantial interannual and interdecadal variability in Sahel rainfall [Lamb and Peppler, 1992; Folland et al., 1991; Ward, 1998; Giannini et al., 2003]. The land surface, in particular vegetation cover and soil moisture, feeds back on precipitation via fluxes of sensible and latent heat and thereby modulates rainfall variability in the Sahel [Charney, 1975; Taylor and Lebel, 1998; Taylor and Ellis, 2006; Xue and Shukla, 1993; Zeng et al., 1999]. An alternative mechanism, affecting precipitation at annual time scales, is the suppression of rainfall following a drought year; this

\footnotetext{
${ }^{1}$ Climate and Land Surface Systems Interactions Centre, Department of Geography, University of Wales Swansea, Swansea, UK.

${ }^{2}$ Department of Geography, University of Leicester, Leicester, UK

${ }^{3}$ Climate and Land Surface Systems Interactions, Centre for Ecology and Hydrology, Natural Environment Research Council, Wallingford, UK.

${ }^{4}$ Climate and Land Surface Systems Interactions, Centre for Ecology and Hydrology, Natural Environment Research Council, Winfrith, UK.
}

Copyright 2006 by the American Geophysical Union. 0094-8276/06/2006GL027065 suppression is associated with enhanced dust generation and subsequent radiative feedbacks in the lower atmosphere [Tegen et al., 1996; Prospero and Nees, 1986]. The suggestion that desertification in the Sahel, i.e., the gradual and irreversible degradation of vegetation caused by livestock and humans, is a major contributing factor to persistent anomalous rainfall [Lamprey, 1988] was not confirmed by the analysis of movements of the desert boundary from satellite data for the 1980s and 1990s [Tucker et al., 1991; Helldén, 1991; Prince et al., 1998] or the analysis of changes in tree density from aerial photographs of 19431994 [Schlesinger and Gramenopoulos, 1996]. At present large uncertainties surround the strength of land-surface memory effects and of feedbacks between the land surface and atmosphere [Koster et al., 2004]. Knowledge of these is essential to understand the causes of temporal variability in precipitation and in particular of the occurrence of drought in the Sahel.

[3] This paper involves constructing a statistical vegetation index simulation at half-degree spatial resolution via least angle regressions of meteorological and satellite observations. The model is constructed with and without vegetation interactions to allow assessments of the impacts of vegetation feedbacks and memory on variability in precipitation and vegetation greenness in the Sahel.

\section{Data}

[4] We analyse monthly satellite-based normalized difference vegetation index (NDVI) data collected by the Advanced Very High Resolution Radiometer (AVHRR) for 1982-1999 sampled to $0.5^{\circ} \times 0.5^{\circ}$ resolution [Hall et al., 2005; S. O. Los et al., Uncertainty analysis of global vegetation, precipitation and temperature data sets with a statistical vegetation index simulation model, in preparation, 2006, hereinafter referred to as Los et al., in preparation, 2006] and monthly ground-based precipitation and temperature data at the same spatial resolution provided by the Climate Research Unit (CRU) for 1901-2000 [Mitchell and Jones, 2005]. The NDVI data (Los et al., in preparation, 2006) are a quantitative measure of vegetation greenness in the Sahel [Tucker et al., 1991]. The version of AVHRR NDVI data we use in the current study is the Fourier Adjusted, Solar and sensor zenith angle corrected, Interpolated and Reconstructed (FASIR) NDVI data (Los et al., in preparation, 2006). This data set is derived from the Pathfinder Advanced Very High Resolution Radiometer (AVHRR) Land (PAL) channel 1 and 2 data that were corrected for Rayleigh scattering and ozone absorption by the atmosphere and sensor degradation and inter-calibration differences in respective AVHRRs aboard the NOAA 7, 9, 11 and 14 satellites [James and Kalluri, 1994]. The additional FASIR 
Table 1. Evaluation of Statistical Vegetation Index Simulation Model Against NOAA-AVHRR FASIR NDVI Data ${ }^{a}$

\begin{tabular}{lcccc}
\hline & RMS Fit & RMS Skill & r Fit & \\
\hline Passive & $\mathbf{0 . 0 2 0}$ & $\mathbf{0 . 0 2 1}$ & $\mathbf{0 . 5 9}$ & r Skill \\
Interactive & $\mathbf{0 . 0 1 8}$ & $\mathbf{0 . 0 1 9}$ & $\mathbf{0 . 7 5}$ & $\mathbf{0 . 5 3}$ \\
Passive 1 & 0.023 & 0.022 & 0.53 & 0.71 \\
Passive 3 & 0.019 & 0.021 & 0.64 & 0.51 \\
\hline
\end{tabular}

${ }^{\mathrm{a}}$ Median of root-mean-square (RMS) errors between modelled mean annual NDVI and observed mean annual FASIR NDVI for the area between $10 \mathrm{~N}$ and $15 \mathrm{~N}$ and $15 \mathrm{~W}$ and $30 \mathrm{E}$. The interactive and passive vegetation simulations represented by equations (1) and (2) are shown in bold type face and are discussed in the text. The interactive vegetation model shows better fit (higher r, lower RMS) and improved skill over the passive vegetation model. The simulations in normal type face show alternatives that were run to establish the optimum number of months to be incorporated in the passive vegetation model. The "Passive 1" simulation is similar to the passive vegetation model but with only one month previous considered; the "Passive 3" simulation considers up to three previous months.

corrections address problems related to residual calibration differences between satellites [Los, 1998], variations in sensor zenith angle and solar zenith angle at time of observation [Los et al., 2005], volcanic aerosols [Los et al., 2000], and short term ( $\leq 2$ months) atmospheric and cloud interferences [Los et al., 2000]. The FASIR NDVI data span a period of 18 years; this period is sufficiently long for the detection of feedbacks and memory effects on monthly to annual time scales with the statistical vegetation index model (see below).

[5] The CRU monthly precipitation and temperature data sets provide global, spatially continuous coverage at $0.5^{\circ} \times$ $0.5^{\circ}$ resolution for 1901-2000 [Mitchell and Jones, 2005]. Missing data are estimated by interpolating climatological mean values with reference to $1961-1990$ and by adding to these anomalies, i.e., the departures from the climatological mean, interpolated from neighboring stations. Interpolation is limited to areas within the "correlation decay distance" from a station; this distance is $1200 \mathrm{~km}$ for temperature data and $450 \mathrm{~km}$ for precipitation data [Mitchell and Jones, 2005]. Grid cells outside the correlation decay distance are represented by the climatological mean. The number of stations per grid cell is provided as an indication of data quality [Mitchell and Jones, 2005].

\section{Method}

[6] We use an extended version of the statistical vegetation index simulation (SVIS) model (Los et al., in preparation, 2006) to investigate associations between vegetation greenness on the one hand and feedback and memory effects on the other. We compare two scenarios, one, the "passive vegetation scenario", assumes no effect of vegetation on precipitation and temperature; and the other, the "interactive vegetation scenario", allows for the possibility that vegetation affects precipitation and temperature; this scenario also incorporates an annual memory. The passive vegetation scenario is given by:

$$
\begin{aligned}
V_{t}=a & +\sum_{i=-2}^{0} b_{t, 2+i} P_{t+i}+\sum_{i=-2}^{0} c_{t, 2+i} T_{t+i} \\
& +\sum_{m=-2}^{-1} d_{t, 2+m} V_{t+m}
\end{aligned}
$$

This scenario takes into account a) the precipitation, $P$, of the current and two previous months $t+i$; b) the surface air temperature, $T$, of the current and previous two months; and c) the NDVI, $V$, of the two previous months. Coefficients are estimated by month, thus year-to-year changes in NDVI for a particular month are linearly related to year-to-year changes in the explanatory variables (NDVI, $T, P$ ) relevant for that month. To distinguish between observations and simulations we further refer to the simulated NDVI, $V_{t}$, as the reconstructed vegetation index, or RVI.

[7] Incorporation of fewer than two previous months in the model resulted in lower correlations between observations and simulations (Table 1); Incorporation of more months resulted in smaller improvements than those obtained by the interactive model discussed below (Table 1).

[8] The interactive vegetation scenario incorporates three additional variables compared to the passive vegetation scenario: a) a feedback between vegetation and climate (precipitation and temperature) and b) an annual memory where the previous year's vegetation growth affects greenness in the following year.

[9] To extract information on feedbacks that resides in the data we introduce the next month's precipitation $P_{t+1}$ and the next month's temperature $T_{t+1}$ into the equation as explanatory variables and see if this improves the model. Note, however, that for these two feedback terms the causal dependencies are reversed. In other words, we assume that a change in vegetation has a measurable effect on the next month's precipitation and temperature and that this effect in turn can be used to improve estimates of vegetation greenness of the current month.

[10] For the annual memory term, further referred to as memory, we use the maximum NDVI of the previous year, $\max \left(V_{y-1}\right)$. The feedback terms are incorporated by changing the upper limit of the counter $i$ for the precipitation and temperature terms in equation (2)

$$
\begin{aligned}
V_{t}=a & +\sum_{I=-2}^{1} b_{t, 2+i} P_{t+i}+\sum_{i=-2}^{1} c_{t, 2+i} T_{t+i} \\
& +\sum_{m=-2}^{-1} d_{t, 2+m} V_{t+m}+e \max \left(V_{y-1}\right)
\end{aligned}
$$

[11] The coefficients for the interactive and passive vegetation scenarios are estimated per $0.5^{\circ} \times 0.5^{\circ}$ cell for each month ( 8 or 11 coefficients $\times 12$ months +1 offset) from 18 years of data. To train the model on a larger number of samples from a wider range of climate and vegetation conditions, the time series of each grid cell was extended with the time series of the two neighboring cells to the North and South; the time series of a $0.5^{\circ}$ by $2.5^{\circ}$ area were thus used to train the model for the central $0.5^{\circ}$ by $0.5^{\circ}$ cell. 
The boundary months at the start of the time series, January and February 1982, use the 1982-1999 mean for November and December as estimates for the preceding year. The boundary months at the end of the time series use the 19821999 mean for the first month of the year. The memory term for the first year also uses the 1982-1999 mean. The error introduced by this simplification is small because the (co-) variance among precipitation, temperature and vegetation during the dormant season is small.

[12] Model coefficients were estimated with least angle regression (LARS), an automatic model-building algorithm that selects a parsimonious set from a group of explanatory variables [Efron et al., 2004]. We base selection of the explanatory variables on the minimum $C p$ criterion, a measure of the maximum variance explained for a minimum amount of explanatory variables included [Draper and Smith, 1998]. Parameters that do not contribute significantly to explained variance in the NDVI are thus removed. Therefore equations (1) and (2) represent the upper bound to the number of variables that are incorporated in the model; for most cases fewer than the maximum number of variables will be selected by LARS to predict the NDVI. The model is flexible and adapts itself to a wide range of conditions, e.g., in areas where the response of vegetation to precipitation is shorter than a month (e.g., grasslands), precipitation of the current month will have the largest impact on in vegetation greenness; in areas where the response is delayed or where a large soil reservoir provides water, precipitation from antecedent months will have a relatively large impact. The number of variables incorporated in the model can vary by month as well. The coefficients selected with LARS are adjusted using a canonical correlation analysis to take into account the effect of errors in both the explanatory and response variables [Draper and Smith, 1998].

[13] Estimating the regression coefficients for each $0.5^{\circ}$ by $2.5^{\circ}$ region allows for a region-specific response of vegetation to climate. A region-specific response could be caused by factors such as topography, slope, aspect, hydrology, land management and nutrient availability. Estimating the regression coefficients by month allows the model to predict a different response of vegetation to changes in precipitation and temperature dependent on the average phenological stage for a particular month of the year.

[14] We use the same optimisation for the interactive vegetation scenario and for the passive vegetation scenario. Note that the passive and active vegetation scenarios would yield similar results in cases where the memory and feedback effects do not improve the model in terms of the minimum $C p$ criterion.

\section{Results and Discussion}

[15] Our analysis shows that the interactive vegetation scenario explains more of the variance in the NDVI and has better predictive skill than the passive vegetation scenario (Table 1). We therefore infer that memory effects at annual time scales and feedback effects at monthly time scales play a rôle in explaining seasonal and interannual variability in vegetation greenness. This rôle becomes clearer when the reconstructed vegetation index, RVI, is calculated for the
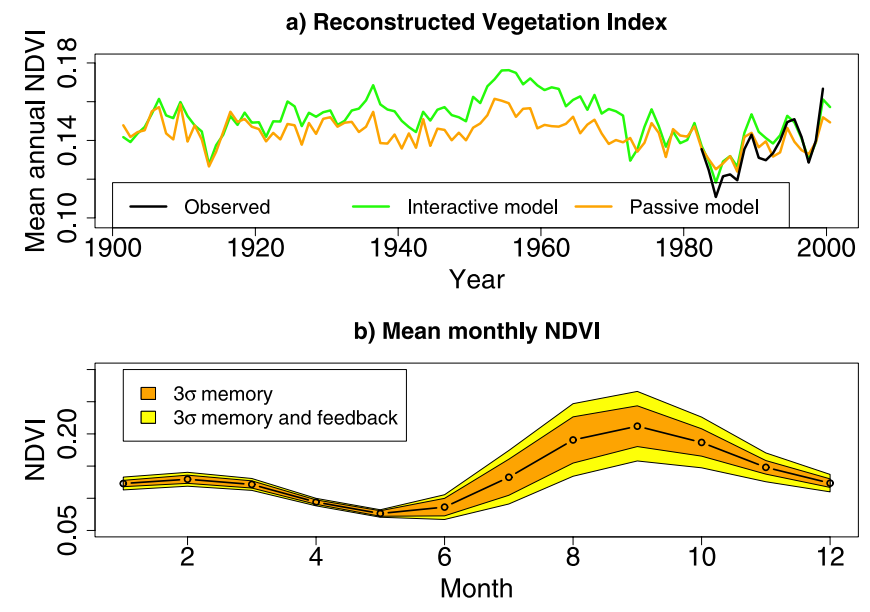

Figure 1. (a) Simulation of mean annual reconstructed vegetation index (RVI) over the 20th century by the passive (light brown solid line, equation (1)) and interactive (green solid line, equation (2)) vegetation scenarios for the area between $14^{\circ}$ and $17^{\circ} \mathrm{N}$ and $15.5^{\circ} \mathrm{W}$ and $10^{\circ} \mathrm{E}$ (see Figure $2 \mathrm{c}$ for location). The observed mean annual NDVI (solid black line) for 1982 until 1999 is shown for comparison. (b) Mean seasonal cycle of the observed normalised difference vegetation index (NDVI) over the period 1982-1999 averaged over the same area as Figure 1a. Shaded brown region represents $\pm 3 \times \sigma$ introduced by memory effects alone and the shaded yellow region represents $\pm 3 \times \sigma$ introduced by memory plus feedback effects combined.

entire 20th century using the CRU temperature and precipitation data as input to the passive and active vegetation model scenarios. The interactive RVI has larger variability over the 20th century than the passive RVI; especially prominent is the enhanced greening during the 1950 s and 1960s in the interactive RVI (Figure 1a). The interactive RVI shows the decline in vegetation reported for the 1970s [Lamprey, 1988] that led to the early hypothesis of desertification in the Sahel; this decline continues until the 1980s after which a partial recovery is shown similar to the NDVI variations detected in satellite data [Tucker et al., 1991]. This recovery was proof that an irreversible southward expansion of the desert did not occur. The 1950s and 1960s appear as an unusually green period during the twentieth century; the subsequent decline to dry conditions was thus unusually severe and this may have contributed to the perceptions of desertification in the 1970s [Lamprey, 1988].

[16] We explore the effects of memory and feedback effects on the seasonality in vegetation greenness for the West African Sahel (Figure 1b; see Figure 2c for location). Here, both effects are of similar magnitude, the maximum for both effects being about $20 \%$ to $25 \%$ of the seasonal range in NDVI. During June and July the memory effect on vegetation slightly exceeds the feedback effect whereas in August and later in the year the effects of the feedbacks become larger.

[17] We estimate the amount of precipitation involved in the feedbacks by comparing two scenarios analogous to the estimation of feedback effects in vegetation with equations (1) and (2). The first scenario does not incor- 

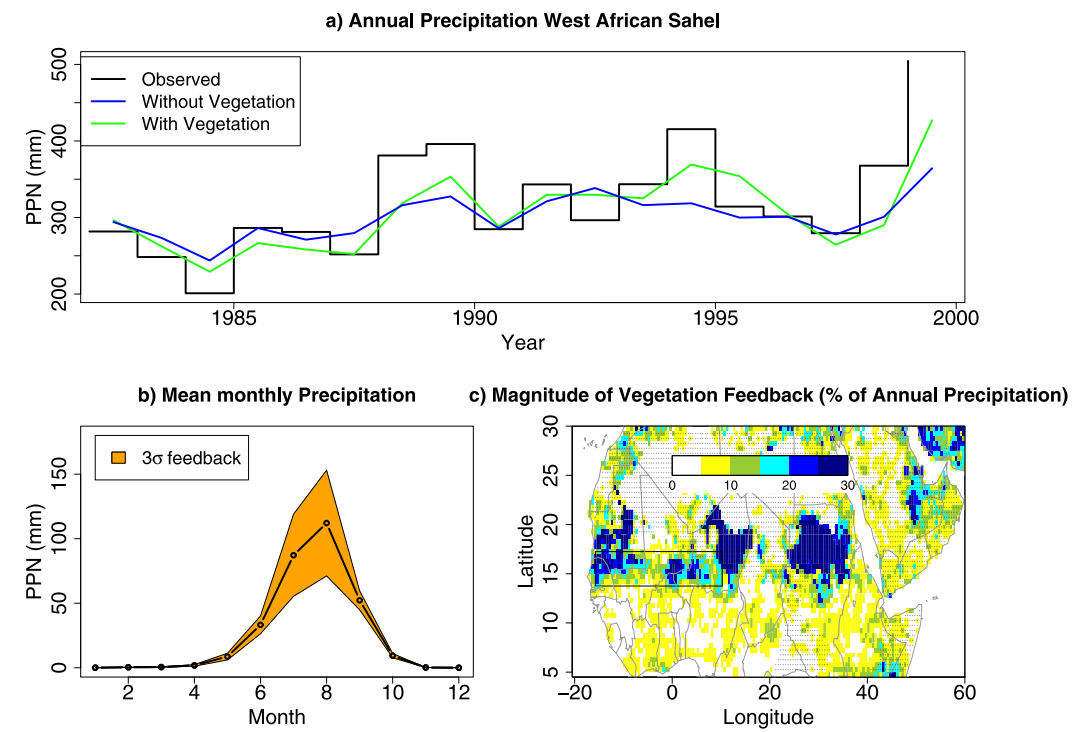

Figure 2. (a) Observed total annual precipitation (PPN; solid black line) for the area between $14^{\circ}$ and $17^{\circ} \mathrm{N}$ and $15.5^{\circ} \mathrm{W}$ and $10^{\circ} \mathrm{E}$ (see Figure $2 \mathrm{c}$ for location) with the total annual precipitation estimated with equation (3) (solid blue line; no vegetation feedbacks assumed) and equation (4) (solid green line; vegetation feedback scenario). (b) Mean seasonal cycle of precipitation over the period 1982-1999 averaged over the same area as (a). Shaded region shows the increased variance as $\pm 3 \times \sigma$ introduced by vegetation feedbacks. (c) Effect of vegetation on precipitation; the difference in variance explained between equations (3) and (4) is expressed as a percentage of the mean annual precipitation. Dotted shading indicates areas with sparse rain gauge coverage (on average less than $50 \%$ of the cells in a $3 \times 3$ window surrounding the area has at least one rain gauge operating every month during 1982-1999).

porate a feedback between vegetation and precipitation and is given by:

$$
P_{t}=a+b P_{y-1}+c_{0} P_{t-2}+c_{1} P_{t-1}
$$

Equation (3) considers the effects on precipitation of the current month, $P_{t}$ of short term moisture variations in the atmosphere and the soil by incorporating the precipitation of the past two months, $P_{t-2}$ and $P_{t-1}$, and of climate oscillators by incorporating the annual rainfall of the previous year, $P_{y-1}$. The second model incorporates the same variables and in addition the observed NDVI of the previous month, $V_{t-1}$ :

$$
P_{t}=a+b P_{y-1}+c_{0} P_{t-2}+c_{1} P_{t-1}+d V_{t-1}
$$

Coefficients for equations (3) and (4) are estimated with the same optimisation procedure used for the passive and interactive vegetation scenarios. The difference between precipitation calculated with and without vegetation feedbacks, in other words, the difference between precipitation modelled with equations (3) and (4), corresponds to the vegetation-precipitation feedback from the interactive vegetation model. The inclusion of the NDVI in equation (4) increases the variance in annual precipitation by about $30 \%$ (Figure 2a). Previous studies provide evidence for both positive and negative feedbacks between the land surface and atmosphere in the Sahel [Taylor and Lebel, 1998; Taylor and Ellis, 2006; Charney, 1975]. Our model simulations indicate both more severe droughts and increased wetness when vegetation feedbacks are incorporated; this implies that for monthly time scales a positive rather than a negative feedback affects rainfall in the (West African) Sahel.

[18] The seasonal variability of vegetation feedback effects on precipitation is shown in Figure $2 b$; an effect is apparent for the entire growing season but the largest effect occurs in July and August when the inter tropical convergence zone (ITCZ) moves northward. During these months the variability in rainfall related to vegetation feedbacks is large and is a substantial proportion of the mean rainfall for these months.

[19] The spatial distribution of vegetation feedback effects expressed as a percentage of the annual precipitation is shown in Figure 2c. Several areas in the Sahel are indicated where the vegetation feedback increases the variance in annual precipitation by at least $30 \%$.

[20] Our study has several limitations. Firstly, our simulations do not account for changes in water use efficiency as a result of increased atmospheric $\mathrm{CO}_{2}$ concentrations over the course of the twentieth century; incorporating this effect is likely to lead to decreased estimates of vegetation greenness during the beginning of the 20th century. This decrease should, however, be similar for both the passive and interactive vegetation scenarios; increases in water use efficiency are therefore unlikely to affect the relative size of our estimates of feedback and memory effects. Secondly, our analysis of feedbacks relies on precipitation estimates from a sparse observation network. Climatological means and interpolations of anomalies are used to estimate missing values [Mitchell and Jones, 2005]. This could affect the detection of linkages between precipitation and vegetation and explain the absence of feedbacks in the central parts of the Sahel east of Lake Chad (Figure 2c). 
Therefore, we are more confident in our results for the western Sahel where a denser station network exists (Figure 2c). Thirdly, we cannot estimate feedbacks between vegetation and precipitation that occur in the same month because we cannot separate the response of vegetation to rainfall from the change in rainfall resulting from vegetation. Consequently, we are likely to be underestimating the feedback between vegetation and precipitation. A similar analysis on data with a shorter time step would lead to improved and likely to larger estimates of feedback effects.

[21] A possible explanation for the annual memory detected in the interactive vegetation scenario, is an investment by plants in roots, shoots and seeds during a wet year and, as a result, an increase in plant productivity during the next. Our interactive scenario predicts that vegetation tends to be greener the year following a year with above average rainfall. It is likely that this enhanced greenness in the interactive RVI during and after periods of increased rainfall reflects a strategy by vegetation to increase productivity when conditions are favorable. The rôle of land-surface memory and feedbacks in explaining increased vegetation greenness and increased precipitation implies that adverse land management practices will decrease rainfall, but not to the extent assumed by the early studies of desertification [Lamprey, 1988] because rainfall clearly depends on other antecedent conditions as well (Figure 2a).

[22] Acknowledgments. This work was carried out by the Climate and Land-Surface System Interaction Centre (CLASSIC), which is funded by the UK Natural Environment Research Council. GPW was funded by CLASSIC and a visit of JDK to Swansea was funded by CLASSIC's visiting scientists programme. We gratefully acknowledge discussions with Chris Huntingford.

\section{References}

Charney, J. G. (1975), The dynamics of deserts and droughts, Q. J.R. Meteorol. Soc., 101, 193-202.

Draper, N. R., and H. Smith (1998), Applied Regression Analysis, 3rd ed., John Wiley, Hoboken, N. J.

Efron, B., T. Hastie, I. Johnstone, and R. Tibshirani (2004), Least angle regression, Ann. Stat., 32, 407-499.

Folland, C. K., D. E. Parker, M. N. Ward, and A. W. Colman (1991), Prediction of deasonal rainfall in the Sahel region of Africa using empirical and dynamical models, J. Forecast., 10, 2-56.

Giannini, A., R. Saravanan, and P. Chang (2003), Oceanic forcing of Sahel rainfall on interannual to interdecadal time scales, Science, 302(7), $1027-1030$.

Hall, F. G., G. J. Collatz, S. O. Los, E. B. de Colstoun, and D. Landis (2005), ISLSCP Initiative II [DVD/CD-ROM], report, NASA, Washington, D. C. (Available at http://islscp2.sesda.com/)

Helldén, U. (1991), Desertification: Time for an assessment?, Ambio, 20, $372-383$.
James, M. E., and S. N. V. Kalluri (1994), The Pathfinder land data set: An improved coarse resolution data set for terrestrial monitoring, Int. J. Remote Sens., 15(17), 3347-3363.

Koster, R. D., et al. (2004), Regions of strong coupling between soil moisture and precipitation, Science, 305, 1138-1141.

Lamb, P. J., and R. A. Peppler (1992), Further case studies of tropical Atlantic surface atmospheric and oceanic patterns associated with subSaharan drought, J. Clim., 5, 476-488.

Lamprey, H. F. (1988), Report on the desert encroachment reconnaissance in northern Sudan, Desertif. Control Bull., 17, 1-7.

Los, S. O. (1998), Estimation of the ratio of sensor degradation between NOAA-AVHRR channels 1 and 2 from monthly NDVI composites, IEEE Trans. Geosci. Remote Sens., 36, 206-213.

Los, S. O., et al. (2000), A global 9-year biophysical land-surface data set from NOAA AVHRR data, J. Hydrometeorol., 1, 183-199.

Los, S. O., P. R. J. North, W. M. F. Grey, and M. J. Barnsley (2005), A method to convert AVHRR normalized difference vegetation index time series to a standard viewing and illumination geometry, Remote Sens. Environ., 99(4), 400-411.

Mitchell, T. D., and P. D. Jones (2005), An improved method of constructing a database of monthly climate observations and associated highresolution grids, Int. J. Climatol, 25, 693-712.

Nicholson, S. (2000), Land surface processes and Sahel climate, Rev. Geophys., 38(1), 117-138.

Prince, S. D., E. B. de Colstoun, and L. L. Kravitz (1998), Evidence from rain-use efficienies does not indicate extensive Sahelian desertification, Global Change Biol., 4, 359-374.

Prospero, J. M., and R. T. Nees (1986), Impact of the North African drought and El Niño on mineral dust in the Barbados trade winds, Nature, 320, $735-738$.

Schlesinger, W. H., and N. Gramenopoulos (1996), Archival photographs show no climate-induced changes in woody vegetation in the Sudan, Global Change Biology, 2, 137-141.

Taylor, C. M., and R. J. Ellis (2006), Satellite detection of soil moisture impacts on convection at the mesoscale, Geophys. Res. Lett., 33, L03404, doi:10.1029/2005GL025252.

Taylor, C. M., and T. Lebel (1998), Observational evidence of persistent convective scale rainfall patterns, Mon. Weather Rev., 126, 1597-1607.

Tegen, I., A. A. Lacis, and I. Y. Fung (1996), The influence of mineral aerosols from disturbed soils on the global radiation budget, Nature, 380, 419-422.

Tucker, C. J., H. E. Dregne, and W. W. Newcomb (1991), Expansion and contraction of the Sahara desert from 1980 to 1990, Science, 253, 299301 .

Ward, N. M. (1998), Diagnosis and short-lead time prediction of summer rainfall in tropical north Africa at interannual and multidecedal time scales, J. Clim., 11, 3167-3191.

Xue, Y., and J. Shukla (1993), The influence of land-surface properties on Sahel climate, I, desertification, J. Clim., 6, 2232-2345.

Zeng, N., J. D. Neelin, K.-M. Lau, and C. J. Tucker (1999), Enhancement of interdecadal climate variability in the Sahel by vegetation interaction, Science, 286, 1537-1540.

S. O. Los, P. R. J. North, and G. P. Weedon, Department of Geography, University of Wales Swansea, Singleton Park, Swansea SA2 8AY, UK (s.o.los@swan.ac.uk)

J. D. Kaduk, Department of Geography, University of Leicester, Leicester LE1 7RH, UK.

C. M. Taylor, Climate and Land Surface Systems Interactions, Centre for Ecology and Hydrology, NERC, Wallingford OX10 8BB, UK.

P. M. Cox, Climate and Land Surface Systems Interactions, Centre for Ecology and Hydrology, NERC, Winfrith DT2 8ZD, UK. 